\title{
Screening for Proteinuria and Chronic Kidney Disease Risk Factors in Kinshasa: A World Kidney Day 2007 Study
}

\author{
Ernest K. Sumaili ${ }^{a}$ d Nazaire M. Nseka ${ }^{a}$ François B. Lepira ${ }^{a}$ \\ Jean Marie Krzesinski d Jean Robert R. Makulo ${ }^{a}$ Justine B. Bukabau ${ }^{a}$ \\ Josée B. Nkoy ${ }^{b}$ Vieux M. Mokoli ${ }^{a}$ Murielle M. Longokolo ${ }^{a}$ \\ Julie A. Owandjalola ${ }^{a}$ Patrick K. Kayembe ${ }^{c}$ \\ ${ }^{a}$ Nephrology Unit, University of Kinshasa, ${ }^{b}$ Saint Joseph Hospital of Kinshasa and ${ }^{\mathrm{C}}$ Medical Epidemiology and \\ Biostatistics Unit, School of Public Health, University of Kinshasa, Kinshasa, Democratic Republic of Congo; \\ ${ }^{\mathrm{d}}$ Division of Nephrology/Transplantation, University of Liège, Liège, Belgium
}

\author{
(C) Free Author \\ Copy - for per- \\ sonal use only \\ PLEASE NOTE THAT ANY \\ DISTRIBUTION OFTHIS AR- \\ TICLE WITHOUT WRITTEN \\ CONSENT FROM S. KARGER \\ AG, BASEL IS A VIOLATION \\ OFTHE COPYRIGHT. \\ Upon request a written per- \\ mission to distribute the PDF \\ file will be granted against \\ payment of a permission fee \\ depending on the number of \\ accesses required. Please \\ contact Karger Publishers, \\ Basel, Switzerland at \\ permission@karger.ch
}

\section{Key Words}

Chronic kidney disease $\cdot$ Diabetes mellitus $\cdot$ Developing countries $\cdot$ Early detection

\begin{abstract}
Background: Although screening programs for chronic kidney disease (CKD) may be of great value, these programs are not yet implemented in the Democratic Republic of Congo. This study focused on proteinuria and examined its prevalence in terms of the number needed to screen for the different risk factors of CKD. Such knowledge would guide the utility of population screening to prevent end-stage renal disease. Methods: A cross-sectional survey was conducted in Kinshasa on the Second World Kidney Day. A sample of 3,018 subjects was interviewed and the following measurements were performed: blood pressure, body mass index, glycemia and urine protein. Logistic regression analysis was used to identify determinants of proteinuria. Results: The prevalence of proteinuria was $17.1 \%$ (95\% Cl 15.8-18.6). Other CKD risk factors identified were: hypertension, diabetes mellitus, obesity and metabolic syndrome. To identify 1 case of proteinuria, one would need to screen 4 persons with dia-
\end{abstract}

betes, 5 persons with hypertension, 4 subjects having metabolic syndrome, 5 persons aged $\geq 72$ years and 9 persons without any of the conditions mentioned above. Age, overweight and diabetes were the strongest factors associated with proteinuria. Conclusions: This study indicates that proteinuria and traditional risk factors for CKD are very prevalent in Kinshasa. Realistic policies to stem these conditions should be a public health priority.

Copyright $\odot 2008$ S. Karger AG, Basel

\section{Introduction}

Chronic kidney disease (CKD) is a worldwide public health problem [1]. To cope with this epidemic, community-based prevention is a necessary strategy and must be based on education, early detection and effective management of CKD and its associated risk factors [2]. Indeed, screening programs are integral components of existing CKD prevention programs. These strategies have already shown promising results in both developed and developing countries [3-5].

\section{KARGER}

Fax +41613061234 E-Mail karger@karger.ch www.karger.com
(C) 2008 S. Karger AG, Base

$1660-2110 / 08 / 1104-0220 \$ 24.50 / 0$

Accessible online at:

www.karger.com/nec
Ernest K. Sumaili

Division of Nephrology, University of Liège

Sart Tilman B-35

BE-4000 Liège (Belgium)

Tel. +32436672 03, Fax +32436672 05, E-Mail skiswaya@yahoo.fr 
However, the effectiveness of the strategy will depend on local infrastructure, finances and organization [6]. Unfortunately, many countries in sub-Saharan Africa including the Democratic Republic of Congo (DRC) have low capacity and resources to accomplish this. In some of them, the health expenditure per capita does not exceed USD 10 per year [7], and this is clearly insufficient to address the challenges posed by the double burden of infectious and noncommunicable diseases (NCD), including CKD.

In addition, the paucity of symptoms and signs in early CKD leads to delays in its recognition [8]. Thus, community strategies to reduce incidence of end-stage renal disease (ESRD) may need to integrate methods of screening and early intervention adapted to the ability of the local team and facilities. Proteinuria is a well-recognized predictor of ESRD and cardiovascular as well as all-cause mortality rates $[9,10]$. Furthermore, several studies suggest that low grades of proteinuria or microalbuminuria might be associated with early CKD even in a nondiabetic population $[10,11]$. Moreover, screening for proteinuria often alerts the physician to the presence of CKD before changes in the glomerular filtration rate (GFR) become apparent and even precede the diagnosis of hypertension or diabetes [12]. Therefore, determination of risk factors for the development of proteinuria might facilitate focused preventive and therapeutic tools to delay the progression of CKD.

Previous studies have suggested that markers for cardiovascular disease are also risk factors for renal disease and proteinuria $[13,14]$. However, those studies were focused primarily on Caucasian, African-American and Asian populations [14, 15]. Also, because Black Africans are at increasing risk of developing ESRD and because CKD epidemiology in sub-Saharan Africa differs from that observed in other regions [16], it is conceivable that risk factors for proteinuria and renal disease among Black Africans might be different. Reasons of these differences are unclear but might be due to genetic and environmental differences.

Well-designed surveys taking benefit of the World Kidney Day (WKD) can serve as a framework for advocacy and community mobilization as well as an opportunity to offer voluntary mass screening to early detect CKD and its associated risk factors [17].

In the present study, we took advantage of the 2007 WKD to describe the prevalence of proteinuria and the number of subjects needed to screen to identify 1 person with proteinuria as well as to evaluate factors associated with proteinuria in the Congolese population.

\section{Material and Methods}

Study Design and Recruitment of Participants

Adults living in Kinshasa, a city of about 10 million inhabitants, were eligible for the 2007 WKD cross-sectional screening for CKD and associated risk factors if they were aged 12 years or older and if they were able to give oral informed consent. The population was informed about the study via community advertisement (TV, radio, newspapers, posters and word-of-mouth) as well as through community and political leaders.

Study Setting, Overview of Procedures and Data Collection

In order to get a large sample nonrepresentative of the adult population living in the city, study sites were selected arbitrarily in different quarters of the city. Those included the University of Kinshasa, the Pax private clinic near a very big bus station at Rond Point Ngaba (North), a secondary school, the Kabalo school in Kintambo (West), a church at Matonge, Saint Joseph, the central part of the city (Center) and a church at Kimbanseke, Saint Boniface (East).

The survey was conducted in March 2007 during 4 consecutive Thursdays from 8 a.m. to 6 p.m. by 75 trained volunteers recruited among medical doctors, laboratory technicians, nurses and medical students.

The subsequent phases of this work are illustrated in figure 1. In brief, the campaign included the following steps: educational message about the kidney (role, diseases and risk factors), registration, recording of general information (family and personal medical history, lifestyle habits), urinalysis, physical examination, blood sugar analysis, interpretation of the results and management.

Knowing that $12.4 \%$ of adults have CKD of all stages in Kinshasa [18], approximately 3,129 subjects were needed to reach this prevalence with error estimate of $2 \%$. Of an intended sample size of three thousand five hundred, 3,134 persons agreed to participate. Among them, 3,018, aged 12 years or more completed the interview and were physically examined.

Interviews collected information on demographic characteristics, daily intake of salt and fruits and vegetables in the diet, smoking habit, alcohol consumption, indigenous herbal remedies use, birth weight knowledge and physical activity. The physical activity during the time of leisure was classified as activity (physical activity of at least $30 \mathrm{~min} /$ day or $4 \mathrm{~h} /$ week) and inactivity in the contrary case. Data about family and medical history of kidney disease, hypertension, diabetes, obesity as well as current treatment were recorded. They were asked to collect a urine sample which was then used to detect proteins with urinary strips (Medi-Test Combi 9) by the readers trained for this purpose. Female subjects were instructed to void a random urine specimen, remote from menstrual periods. Proteinuria was defined as $1+$ or greater. For subjects having leukocyturia or positive dipstick nitrite test, classification as having proteinuria required its confirmation after treatment with antibiotics.

Body weight, height and waist/hip circumference were measured. Height was taken to the nearest $0.1 \mathrm{~cm}$ with a portable stadiometer (Seca) and weight was measured to the nearest $0.1 \mathrm{~kg}$ on a mechanical scale (Seca).

Thereafter, the subjects were allowed to relax for $5 \mathrm{~min}$ in a sitting position before determination of blood pressure. Blood pressure was measured twice in the right or left arm using an au- 
Fig. 1. Illustration of the phases of the free mass screening of proteinuria and associated risk factors of CKD at the 2007 WKD ('Are Your Kidneys OK') in Kinshasa. $\mathrm{HBP}=$ High blood pressure.

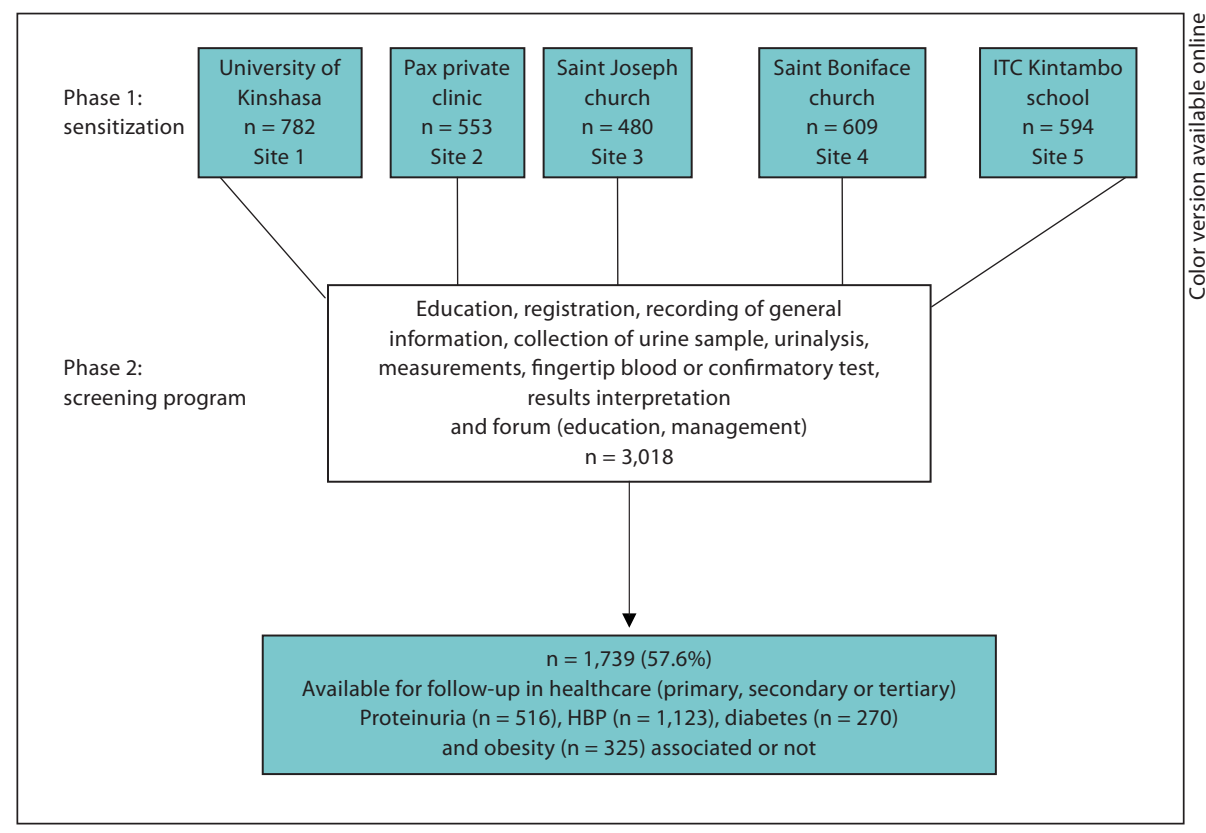

tomatic machine (Omron M 5-1) at heart level. Hypertension was defined by an average of systolic blood pressure $\geq 140 \mathrm{~mm} \mathrm{Hg}$ or diastolic blood pressure $\geq 90 \mathrm{~mm} \mathrm{Hg}$ and/or concomitant use of antihypertensive medications by self-report (known hypertensive) [19].

The body mass index (BMI) was calculated from the measured height (in meters) and weight (in kilograms) and was categorized as not obese $(<25)$, overweight $(25-29.9)$ or obese $(\geq 30)$ according to the 2000 WHO criteria [20]. Metabolic syndrome was defined simply as abdominal obesity (waist circumference $>102 \mathrm{~cm}$ for males and $>88 \mathrm{~cm}$ for females) associated with blood pressure $\geq 130 / 85 \mathrm{~mm} \mathrm{Hg}$ and fasting glucose $\geq 110 \mathrm{mg} / \mathrm{dl}$ [21].

Fingertip blood (Ascensia Entrust glucometer; Bayer) for fasting glucose or random glucose was also performed. The diagnosis of diabetes was confirmed after repeat testing on a subsequent week (fasting glucose values of $\geq 126 \mathrm{mg} / \mathrm{dl}$ ) or a positive history of diabetes and/or concomitant use of antidiabetic medications by self-report (known diabetic) [22].

Kidney damage was defined as the presence of $\geq 1+$ protein (equivalent to $\geq 30 \mathrm{mg} / \mathrm{dl}$ ).

\section{Statistical Analysis}

Results are presented as numbers, percentages or means \pm SD. Two-sample Student's t test and $\chi^{2}$ test were used for comparison of means and proportions where appropriate. The crude (unadjusted) and adjusted odds ratios (OR) were estimated to assess the relationship between the risk factors and kidney damage (proteinuria) using a stepwise logistic regression analysis. The exposure variables included age, gender, smoking, alcohol consumption, indigenous herbal remedies, birth weight knowledge, family history (diabetes, hypertension, obesity and kidney disease), diabetes, hypertension and BMI. All data analysis and calculations except the $\chi^{2}$ test were performed by using the standard statistical package (SPSS, version 13.0). $\chi^{2}$ test was performed in the dialog box using Medcalc, version 9.1.01. The zero hypothesis was rejected at $\mathrm{p}<0.05$.

All rules of confidentiality were complied with, including collection of information and physical examination. The study protocol and related documents were approved by the provincial and national levels of the Ministry of Health.

\section{Results}

\section{Characteristics of the Study Population}

More than half $(57.6 \%)$ of the examined subjects had at least 1 of the signs of NCD (fig. 1). Table 1 shows the sociodemographic characteristics of the participants. The age range was $12-85$ years (mean $44.3 \pm 15.3$, median 45). Some statistically significant differences between male and female subjects were observed. Female subjects were older (mean $46.5 \pm 14.8$ vs. $42.8 \pm 15.5$ years, $\mathrm{p}<0.001$ ). Physical inactivity and a family history of obesity were more frequent among them than in male subjects. In contrast, proportions of those with low or high birth weight, smoking habit, herbal remedies use, high educational level and employment were more prevalent in male than in female subjects $(\mathrm{p}<0.01)$.

\section{Prevalence of Proteinuria and Number Needed to Screen to Identify One Person with Findings}

Proteinuria (regardless of kidney function) was detected in $17.1 \%$ (95\% CI $15.8-18.6)$ of participants but 
Table 1. Characteristics of the study population by gender

\begin{tabular}{lccc}
\hline Clinical features & Males $(\mathrm{n}=1,767)$ & Females $(\mathrm{n}=1,239)$ & p value \\
\hline Age & $42.8 \pm 15.5$ & $46.5 \pm 14.8$ & $<0.001$ \\
Age range, years & & & \\
$\quad$ 12-29 years & $527(29.8)$ & $237(19.2)$ & $<0.0001$ \\
$\quad 30-44$ years & $445(25.2)$ & $262(21.2)$ & 0.01 \\
$\quad 45-56$ years & $375(21.2)$ & $375(30.4)$ & $<0.0001$ \\
$\quad 57-85$ years & $420(23.8)$ & $333(27)$ & 0.05 \\
Low or high birth weight ${ }^{1}$ & $253(22.9)$ & $151(19.6)$ & 0.03 \\
History of hypertension & $235(13.3)$ & $304(24.7)$ & $<0.0001$ \\
Detection rate of hypertension & $384(21.7)$ & $199(16.1)$ & 0.0002 \\
History of diabetes mellitus & $78(4.4)$ & $54(4.4)$ & 0.9 \\
Detection rate of diabetes & $58(3.2)$ & $80(4.1)$ & 0.2 \\
Smoking currently & $213(10.3)$ & $23(1.8)$ & $<0.0001$ \\
Alcohol consumption currently & $886(50.1)$ & $366(29.5)$ & $<0.0001$ \\
Herbal remedies use currently & $655(37.4)$ & $335(27.6)$ & $<0.0001$ \\
Physical inactivity & $432(26.2)$ & $536(46.8)$ & $<0.0001$ \\
Family history of hypertension & $109(6.2)$ & $94(7.7)$ & 0.1 \\
Family history of diabetes mellitus & $430(25.6)$ & $279(24.1)$ & 0.3 \\
Family history of obesity & $301(17.5)$ & $297(25.1)$ & $<0.0001$ \\
Lack of employment & $963(54.5)$ & $923(74.8)$ & $<0.0001$ \\
High educational level & $1,075(60.8)$ & $304(24.6)$ & $<0.0001$ \\
\hline
\end{tabular}

Values expressed as numbers and percentages in parentheses or means $\pm \mathrm{SD}$, as appropriate. Data from the 2007 WKD ('Are Your Kidneys OK') in Kinshasa. ${ }^{1}$ Low birth weight: $<2.5$ kg; high birth weight: $\geq 3.8$ kg.

only 21 (4\%) were aware of their condition. The frequency distribution of dipstick proteinuria without hematuria is given in table 2. Among subjects with proteinuria, $15.3 \%(n=463)$ of the total population exhibited isolated proteinuria and the remaining $1.7 \%(\mathrm{n}=53)$ of the study population had proteinuria with hematuria. Isolated hematuria, defined as dipstick hematuria $\geq 1+$, was found in $3.8 \%(\mathrm{n}=114)$ of the total population.

In addition, the prevalence of proteinuria among other CKD risk factors screened is shown in figure 2. Furthermore, the prevalence of various states of proteinuria in 7 different target groups (whole population, diabetics, hypertensives, metabolic syndrome cases, obese, overweight subjects and persons without NCD) for 7 age categories $(12-21,22-31,32-41,42-51,52-61$, $62-71$ and $\geq 72$ years of age) is displayed in table 3 . The prevalence estimates are also presented as the number of persons one would need to screen (number needed to screen to identify 1 participant with the constellation of findings specified in table 3). Overall, proteinuria becomes more prevalent with older age in most different target groups and the number needed to screen is lower.
Table 2. Distribution of degree of proteinuria of study population $(\mathrm{n}=3,018)$

\begin{tabular}{lrr}
\hline Proteinuria & $\mathrm{n}$ & $\%$ \\
\hline$+1(30 \mathrm{mg} / \mathrm{dl})$ & 449 & 14.8 \\
$+2(100 \mathrm{mg} / \mathrm{dl})$ & 53 & 1.7 \\
$+3(500 \mathrm{mg} / \mathrm{dl})$ & 14 & 0.4 \\
\hline All patients $(\geq+1)$ & 516 & 17.1
\end{tabular}

Data from the 2007 WKD ('Are Your Kidneys OK') in Kinshasa.

\section{Determinants of Proteinuria}

Risk factors associated with proteinuria are summarized in table 4. Diabetes mellitus (adjusted OR 1.3, 95\% CI 1.02-1.8; p < 0.05), overweight (adjusted OR 1.2, 95\% CI 1.02-1.6; $\mathrm{p}<0.05$ ) and increasing age (adjusted OR 1.4 for over 50 years vs. $<50$ years, $95 \%$ CI $1.1-1.7 ; \mathrm{p}=0.01$ ) were independent factors associated with proteinuria. The OR for proteinuria increased proportionately with age (data not shown). However, male gender, family and 


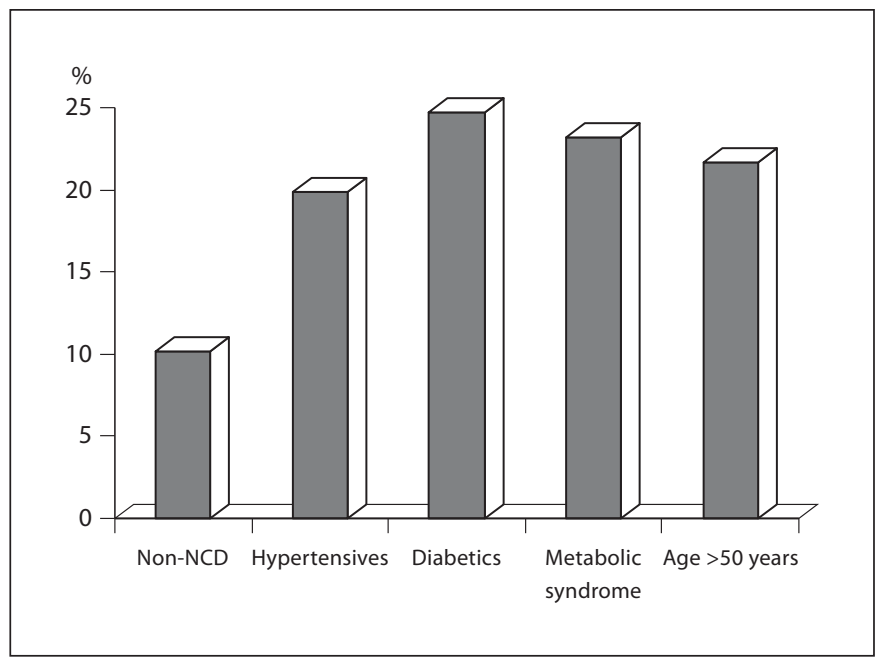

Fig. 2. Prevalence of proteinuria in non-NCD persons, hypertensives, diabetics, metabolic syndrome subjects and participants $>50$ years. Data from the 2007 WKD ('Are Your Kidneys OK') in Kinshasa. medical history of kidney disease, hypertension or diabetes, smoking and herbal remedies use were not significant predictors for the presence of proteinuria in this study.

\section{Discussion}

A call to action on the $2007 \mathrm{WKD}$ [17] prompted us to identify that a significant number of the adult population of Kinshasa has proteinuria and other CKD risk factors such as hypertension, diabetes and/or obesity. This fact is well illustrated by our recent report of increasing number of CKD and associated risk factors in the general population of Kinshasa [18].

Over $15 \%$ of our study subjects had proteinuria. This value is much higher than the $11 \%$ found in Bolivia [5] and the $8.7 \%$ in NHANES III [3], but lower than the 55, 35 and 26\% observed in Tiwi islanders [23], South Africans [24] and among Zuni Indians [25], respectively. This

Table 3. Prevalence of proteinuria in 7 study groups by age (in decades)

\begin{tabular}{|c|c|c|c|c|c|c|c|c|}
\hline & \multicolumn{8}{|c|}{ Age group, years } \\
\hline & $12-21$ & $22-31$ & $32-41$ & $42-51$ & $52-61$ & $62-71$ & $\geq 72$ & Total \\
\hline \multicolumn{9}{|c|}{ Whole population } \\
\hline Proteinuria & $114(8.7)$ & $715(11.4)$ & $493(18.6)$ & $602(18.2)$ & $613(18.9)$ & $405(22.4)$ & $76(19.7)$ & $3,018(17.1)$ \\
\hline NNS & 11 & 9 & 5 & 5 & 5 & 4 & 5 & \\
\hline \multicolumn{9}{|l|}{ Diabetics } \\
\hline Proteinuria & 5 & $31(12.9)$ & $36(27.8)$ & $50(28)$ & $82(28)$ & $59(25.4)$ & $7(14.3)$ & $270(24.8)$ \\
\hline NNS & & 8 & 4 & 4 & 4 & 4 & 7 & 4 \\
\hline \multicolumn{9}{|l|}{ Hypertensives } \\
\hline Proteinuria & 14 & $86(11.6)$ & $103(10.7)$ & $246(18.7)$ & $348(20.1)$ & $260(28.5)$ & $66(19.7)$ & $1,123(19.9)$ \\
\hline NNS & & 9 & 9 & 5 & 5 & 4 & 5 & 5 \\
\hline \multicolumn{9}{|c|}{ Metabolic syndrome } \\
\hline Proteinuria & & $9(1.1)$ & $11(9.1)$ & $51(19.6)$ & $57(28.1)$ & $25(20)$ & $6(50)$ & $159(22.6)$ \\
\hline NNS & & 9 & 11 & 5 & 4 & 5 & 2 & 4 \\
\hline \multicolumn{9}{|l|}{ Obese } \\
\hline Proteinuria & 1 & $27(7.4)$ & $40(15)$ & $96(25)$ & $97(25.8)$ & $43(16.3)$ & $8(37.5)$ & $312(21.4)$ \\
\hline NNS & & 14 & 7 & 4 & 4 & 6 & 3 & 5 \\
\hline \multicolumn{9}{|l|}{ Overweight } \\
\hline Proteinuria & $8(12.5)$ & $60(15)$ & $90(23.3)$ & $172(19.8)$ & $182(19.2)$ & $87(33.3)$ & $8(25)$ & 607 (21.6) \\
\hline NNS & 8 & 7 & 4 & 5 & 5 & 3 & 4 & 5 \\
\hline \multicolumn{9}{|l|}{ Non-NCD } \\
\hline Proteinuria & $93(8.6)$ & $538(10.4)$ & $318(13.5)$ & $281(10.3)$ & $199(9.0)$ & 107 (14) & $20(10)$ & $1,556(10.9)$ \\
\hline NNS & 12 & 10 & 7 & 10 & 11 & 7 & 10 & 9 \\
\hline
\end{tabular}

Values expressed as numbers and percentages in parentheses. NNS = Number needed to screen. 
Table 4. Determinants of proteinuria (univariate and multivariate analysis)

\begin{tabular}{|c|c|c|c|c|c|c|}
\hline \multirow{2}{*}{$\begin{array}{l}\text { Risk factors } \\
\text { proteinuria (Medi-Test Combi 9) }\end{array}$} & \multicolumn{3}{|c|}{ Univariate analysis } & \multicolumn{3}{|c|}{ Multivariate analysis } \\
\hline & OR & $95 \% \mathrm{CI}$ & $\mathrm{p}$ value & OR & $95 \% \mathrm{CI}$ & $\mathrm{p}$ value \\
\hline Hypertension vs. no & 1.3 & $1.1-1.6$ & 0.001 & 1.07 & $0.8-1.3$ & 0.5 \\
\hline Diabetes vs. no & 1.5 & $1.1-2.1$ & 0.003 & 1.3 & $1.02-1.8$ & 0.03 \\
\hline Overweight vs. no & 1.3 & $1.1-1.7$ & 0.005 & 1.2 & $1.02-1.6$ & 0.03 \\
\hline Metabolic syndrome vs. no & 1.5 & $1.03-2.2$ & 0.03 & 1.4 & $0.9-2.1$ & 0.1 \\
\hline Age $<50$ vs. $\geq 50$ years & 1.5 & $1.2-1.8$ & 0.000 & 1.4 & $1.1-1.7$ & 0.002 \\
\hline
\end{tabular}

discrepancy between studies may be due partly to various definitions (microalbuminuria vs. dipstick proteinuria) and criteria of selection (random vs. without random sample or/and high risk population vs. whole population) applied in each survey.

We recognize that dipstick proteinuria has limited sensitivity and specificity [26]. However, despite the fact that the present study used dipstick proteinuria, it is of great prognostic value. For example, screening with the urine dipstick test for proteinuria has been used successfully in Japan since 1972, targeting every child and worker, as well as since 1983 for every resident over 40 years old [27]. Moreover, a survey undertaken in Okinawa after 17 years of follow-up indicates that individuals with dipstick-positive proteinuria are at increased risk of developing CKD, in fact in proportion to the severity of proteinuria [28]. Sam et al. [29] have demonstrated that trace dipstick proteinuria usually means microalbuminuria. Indeed, in their survey, a negative urinalysis for proteinuria excluded microalbuminuria in $87 \%$ and proteinuria in $78 \%$ of cases. In addition, more recently, it has also become apparent that dipstick proteinuria is more indicative of microalbuminuria than macroalbuminuria [30]. This is a fact because of the subjects that were trace, $1+$ or $2+$ positive on a dipstick protein, 61,71 and $41 \%$, respectively, had microalbuminuria, whereas only 1,7 and $50 \%$, respectively, had macroalbuminuria. It is likely that the majority of our cases that were positive for proteinuria in fact had microalbuminuria.

In our study, 9 adults that do not have NCD need to be screened to identify 1 individual with proteinuria. This number decreases in certain subgroups, amounting to 4 in diabetics, 5 in hypertensives, 4 in persons with metabolic syndrome or 5 in persons $>50$ years. The NHANES III yielded similar results [14] especially in the diabetic group. Yet, some differences exist between the 2 studies. The testing method for albuminuria was different. In addition, it is possible that the relatively low prevalence of albuminuria observed in their survey [14] compared to ours results from the use of antihypertensive therapy (specifically, angiotensin-converting enzyme inhibitor and angiotensin receptor blocker use), which may reduce the number of patients with proteinuria.

In our present survey, diabetes, overweight and increasing age were independently associated with the presence of proteinuria. Age is a recognized risk factor for renal disease [31]. This is attributed partly to glomerular obsolescence and decreased renal vascular flow [32]. Other factors associated with proteinuria in univariate but not in multivariate analysis in our study were hypertension and metabolic syndrome. Several studies already demonstrated the relationship between hypertension as well as increasing BMI and proteinuria [33]. For example, in prospective studies, such as the Multiple Risk Factor Intervention Trial (MRFIT), each 9-mm Hg increase in DBP was associated with an OR of 1.37 for the presence of dipstick-positive proteinuria [34]. Plausible mechanisms have focused on the elevation in the pressure transmitted to glomeruli, which might result in sclerosis and proteinuria [35]. Moreover, as reported by Chen et al. [36], metabolic syndrome is associated with higher risk for proteinuria. We have confirmed this. The exact mechanism of this proteinuria/albuminuria-associated cardiovascular risk remains unknown, but might be due to endothelial dysfunction [37].

However, some risk factors for proteinuria such as family and medical history of kidney disease, low birth weight and smoking, reported elsewhere $[15,38]$, were not observed in the present study. The lack of awareness of renal disease by both health workers and lay population can partly explain this observation. Indeed, in our study, a little more than three quarters of the population does not know the localization, role or even name of the kidney in their mother tongue. In addition, most of our study population did not have birth certificates or knowledge of their weight at birth. The reason why tobacco was 
not associated with proteinuria remains unclear and deserves further study.

\section{Strength and Limitations of our Study}

The strength of this study is that it includes a large sample of the general population of Kinshasa and that we used standardized methods of data collection. Already, by doing this study, we have improved awareness of CKD in the DRC and also addressed the fear of disease surveillance formerly observed in this population.

However, there are some limitations and constraints that must be considered. First, a selection bias may exist because subjects who volunteered to participate in the screening program might be more likely to have the risk factors that we studied, including proteinuria. Second, as in any cross-sectional study, causation cannot be established because the sequence of events between exposure and outcome is not defined. Third, because of lack of resources, our study used simply dipstick methods to screen for proteinuria, which has detection limits as mentioned earlier [26]. Indeed, common causes [26,39] for false positives by dipstick test may be seen in patients with gross hematuria, contamination with antiseptic agents (chlorhexidine, benzalkonium chloride), alkaline urine $\mathrm{pH}$, highly concentrated urine and, conversely, false negatives may occur in patients with dilute urine or in disease states in which predominant protein is not albumin (dipstick protein being sensitive only to albumin). In addition, proteinuria can occur transiently in response to hemodynamic stress (severe exercise, fever and convulsion), dehydration, cold exposure, congestion heart failure, urinary tract infection and during menstruation or pregnancy in women [40]. It is also likely that some positive proteinuria among subjects with neither hypertension nor diabetes might be due to chronic glomerulonephritis which remains a major cause of ESRD in the DRC $[6,41]$. Furthermore, some cases of proteinuria in this study might be due to HIV or hepatitis $\mathrm{B}$ or $\mathrm{C}$ virus infections which are prevalent in this country [41]. Yet, this study did not address the specific causes of proteinuria in individual subjects. Consequently, the only sign of CKD for those subjects at early stage is urinary abnormalities.

Fourth, except for proteinuria associated with pyuria, indicators of kidney damage were defined based on a single measurement. In K/DOQI [42] and K/DIGO [2] guidelines, the definition of $\mathrm{CKD}$ requires the persistence of kidney damage for at least 3 months. Also, studies based on NHANES III indicate that in repeated measurement, only $63.2 \%$ of those with albuminuria would have persistently positive results [3]. Hence, the single measurement of proteinuria in our study might overestimate its prevalence.

Fifth, distribution of proteinuria across categories of estimated GFR could be informative and very useful. Unfortunately, we have not measured serum creatinine in this study due to pragmatic and economic reasons. However, proteinuria remains a good risk marker for developing ESRD [27].

To conclude, the present work, despite possible methodological limitations, emphasizes that proteinuria and CKD risk factors such as hypertension, diabetes and obesity are highly prevalent in Kinshasa, while awareness of NCD is very low. This study confirms diabetes, overweight and age as the strongest independent risk factors associated with proteinuria. Also, prevalence of proteinuria among subjects with neither diabetes nor hypertension is high as in Japan [27] but not in Caucasian populations. If confirmed, these data support the idea that annual urinalysis screening for the whole population in the DRC might be cost-effective. This is in contrast to the report of Boulware et al. [43] who affirm that annual screening for proteinuria in US adults was not cost-effective because the prevalence of proteinuria was very low. Furthermore, urinary albumin and creatinine ratio testing as well as microalbuminuria are more expensive than dipstick proteinuria. Therefore, urine dipstick test for proteinuria is suitable as a first step for most countries or races that have a high prevalence of proteinuria such as the DRC. Further studies to assess the performance of dipstick proteinuria as well as its cost-effectiveness analysis and including estimated GFR in this country are needed to develop adapted preventive strategies. This targeted prevention strategy could result in the reduction of cardiovascular events as well as the alarming incidence of ESRD.

\section{Acknowledgments}

This work was supported by Novo Nordisk (Denmark), Celtel Congo and Grand Hotel of Kinshasa. We thank Prof. Eric P. Cohen and Nestor M. Pakasa for review of this manuscript.

The authors are grateful to the medical doctors, medical students and nurses (trained volunteers); medical doctors: A. Longo, C. Zinga, R. Kianu, S. Mukendi, F. Muamba, Z. Nsumbu, F. Muanda, P. Phaka and M. Basoluka; nurses and laboratory technicians: S. Kolemba, M. Meta, P. Mungalu, A. Nsele, C. Mbo, A. Luwidi and E. Keta.

We are indebted to Prof. F. Ilondo, medical students and the staff of the Catholic church (Saint Joseph, Saint Boniface), the Pax private clinic, the Kabalo School and the staff of the University of Kinshasa for their assistance. 


\section{References}

1 Eknoyan G, Lameire N, Barsoum R, Eckardt KU, Levin N, Locatelli F, MacLeod A, Vanholder R, Walker R, Wang H: The burden of kidney disease: improving global outcomes. Kidney Int 2004;66:1310-1314.

$\checkmark 2$ Levey AS, Atkins R, Coresh J, Cohen EP, Collins AJ, Eckardt KU, Nahas ME, Jaber BL, Jadoul M, Levin A, Powe NR, Rossert J, Wheeler DC, Lameire N, Eknoyan G: Chronic kidney disease as a global public health problem: approaches and initiatives. A position statement from Kidney Disease Improving Global Outcomes (KDIGO). Kidney Int 2007;72:247-259.

-3 Coresh J, Astor BC, Greene T, Eknoyan G, Levey AS: Prevalence of chronic kidney disease and decreased kidney function in the adult US population: Third National Health and Nutrition Examination Survey. Am J Kidney Dis 2003;41:1-12.

$\checkmark 4$ Hillege HL, Fidler V, Diercks GF, van Gilst WH, de Zeeuw D, van Veldhuisen DJ, Gans RO, Janssen WM, Grobbee DE, de Jong PE; Prevention of Renal and Vascular End-Stage Disease (PREVEND) Study Group: urinary albumin excretion predicts cardiovascular and non-cardiovascular mortality in general population. Circulation 2002;106:17771782.

$\checkmark 5$ Plata R, Silva C, Yahuita J, Perez L, Schieppati A, Remuzzi G: The first clinical and epidemiological programme on renal disease in Bolivia: a model for prevention and early diagnosis of renal diseases in the developing countries. Nephrol Dial Transplant 1998;13: 3034-3036.

6 Krzesinski JM, Sumaili EK, Cohen EP: How to tackle the avalanche of chronic kidney disease in sub-Saharan Africa: the situation in the Democratic Republic of Congo as an example. Nephrol Dial Transplant 2007;22: 332-335.

7 Barsoum RS: Epidemiology of end stage renal disease (ESRD): a worldwide perspective; in El Nahas M (ed): Kidney Diseases in the Developing World and Ethnic Minorities. New York, Taylor and Francis, 2005, pp 113.

8 Ifudu O, Friedman EA: Management chronic renal insufficiency: intertwined roles of non-nephrologist and nephrologist. J Natl Med Assoc 2003;95:43-54.

9 Iseki K, Ikemiya V, Fukiyama K: Risk factors of end stage renal disease and serum creatinine in a community-based mass screening. Kidney Int 1997;51:850-854

- 10 Pinto-Sietsma SJ, Jannsen WMT, Hillege HL, Navis G, de Zeeuw D, de Jong PE: Urinary albumin excretion is associated with renal functional abnormalities in non-diabetic population. J Am Soc Nephrol 2000;11: 1882-1888.
11 Hillege HL, Janssen WM, Bak AA, Diercks GK, Grobbee DE, Crijns HJ: Microalbuminuria is common also in a nondiabetic nonhypertensive population and an independent indicator of cardiovascular risk factors and cardiovascular morbidity. J Intern Med 2001 249:519-526.

12 Brantsma AH, Bakker SJ, de Zeeuw D, de Jong PE, Gansevoort RT: Urinary albumin excretion as a predictor of the development of hypertension in the general population. J Am Soc Nephrol 2006;17:331-335.

13 Fox CS, Larson MG, Leip EP, Culleton B, Wilson PWF, Levy D: Predictors of new-onset kidney disease in a community-based population. JAMA 2004;291:844-850.

14 Garg AX, Kiberd BA, Clark WF, Haynes RB, Clase CM: Albuminuria and renal insufficiency prevalence guidelines population screening: results from the NHANES III. Kidney Int 2002;61:2165-2175.

15 Ramirez SPB, McClellan W, Port FK, Hsu SI: Risk factors for proteinuria in a large, multiracial, Southeast Asian population. J Am Soc Nephrol 2002;13:1907-1917.

16 Arogundade FA, Barsoum RS: CKD prevention in sub-Saharan Africa: a call for governmental, nongovernmental, and community support. Am J Kidney Dis 2008;51:515-523.

17 Couser WG, Shah S, Kopple J, Beerkens P, Wilson A, Feehally J, Reiser T, Riella M: A call to action on World Kidney Day, 8 March 2007. Kidney Int 2007;71:369-370.

18 Sumaili EK, Krzesinski JM, Zinga CV, Cohen EP, Delanaye P, Munyanga SM, Nseka NM: Prevalence of chronic kidney disease in Kinshasa, the Democratic Republic of Congo. Abstract presented to the ERA-EDTA XLV Congress in Sweden, May 10-13, 2008;Stockholm. http://www.postersessiononline.eu/aula_vis.asp (accessed July 14, 2008).

19 Chobanian AV, Bakris GL, Black HR, Cushman WC, et al: The Seventh Report of the Joint National Committee on Prevention, Detection, Evaluation, and Treatment of High Blood Pressure: the JNC 7 report. JAMA 2003;289:2560-2572.

20 Obesity: preventing and managing the global epidemic. Report of a WHO consultation. World Health Organ Tech Rep Ser 2000;894: i-xii, 1-253.

21 Expert Panel on Detection, Evaluation, and Treatment of High Blood Cholesterol in Adults: Executive Summary of the Third Report of the National Cholesterol Education Program (NCEP) Expert Panel on Detection, Evaluation, and Treatment of High Blood Cholesterol in Adults (Adult Treatment Panel III). JAMA 2001;285:24862497.
22 Expert Committee on the Diagnosis and Classification of Diabetes Mellitus: Report of the Expert Committee on the Diagnosis and Classification of Diabetes Mellitus. Diabetes Care 2003;26(suppl 1):S5-S20.

23 McDonald SP, Maguire GP, Hoy WE: Renal function and cardiovascular risk markers in a remote Australian Aboriginal community. Nephrol Dial Transplant 2003;18:15551561.

24 Katz IJ, Hoy WE, Kondalsamy-Chennakesavan S, Gerntholtz T, Scheppingen J, Sharma S, Butler O, Shezi E, Mdleleni G, Mthombeni D: Chronic kidney disease management: what can we learn from South African and Australian Efforts? Blood Purif 2006;24: 115-122.

25 Brown WW, Peters RM, Ohmit SE, Keane WF, Keane WF, Collins A, Chen SC, King K, Klag MJ, Molony DA, Flack JM: Early detection of kidney disease in community settings. The Kidney Early Evaluation Program (KEEP). Am J Kidney Dis 2003;42:22-35.

26 Davidson MB, Smiley JF: Relationship between dipstick positive proteinuria and albumin:creatinine ratios. J Diabetes Complications 1999;13:52-55.

27 Yamagata K, Iseki K, Nitta K, Imai H, Lino Y, Matsuo S, Makino H, Hishida A: Chronic kidney disease perspectives in Japan and the importance of urinalysis screening. Clinic Exp Nephrol 2008;12:1-8.

-28 Iseki K, Ikemiya Y, Iseki C, Takishita S: Proteinuria and the risk of developing end stage renal disease. Kidney Int 2003;63:14681474 .

29 Sam R, Shaykh MS, Pegoraro AA, Khalil V, Hristea I, Singh AK, Arruda JAL, Dunea G: The significance of trace proteinuria. Am J Nephrol 2003;23:438-441.

30 Konta T, Hao Z, Takasaki S, Abiko H, Ishikawa M, Takahashi T, Ikeda A, Ichikawa K, Kato T, Kawata S, Kubota I: Clinical utility of trace proteinuria for microalbuminuria screening in the general population. Clin Exp Nephrol 2007;11:51-55.

-31 Neugarten J, Gallo G, Silbiger S, Kasiske B: Glomerulosclerosis in aging humans is not influenced by gender. Am J Kidney Dis 1999; 34:884-888.

\$2 Mulder WJ, Hillen HF: Renal function and renal disease in the elderly. Part II. Eur J Intern Med 2001;12:327-333.

33 United States Renal Data System: Incidence and prevalence of ESRD; in USRDS 1999 Annual Data Report. Bethesda, National Institutes of Health, National Institute of Diabetes and Digestive and Kidney Diseases, 1999, pp 25-38. 
34 Grimm RH, Svendsen KH, Kasiske B, Keane WF, Wahi MM, MRFIT Research Group: Proteinuria is a risk factor for mortality over 10 years follow-up. Multiple Risk Factor Intervention Trial. Kidney Int 1997;52(suppl 63):S10-S14.

-35 Bianchi S, Bigazzi R, Campese VM: Microalbuminuria in essential hypertension: significance, pathophysiology and therapeutic implications. Am J Kidney Dis 1999;34: 973-995.

-36 Chen J, Muntner P, Hamm LL, Jones DW, Batuman V, Fonseca V, Whelton PK, He J: The metabolic syndrome and chronic kidney disease in US adults. Ann Intern Med 2004;140: 167-174.
37 Stehouwer CD, Henry RM, Dekker JM, Nijpels G, Heine RJ, Bouter LM: Microalbuminuria is associated with impaired brachial artery flow-mediated vasodilation in elderly individuals without and with diabetes: further evidence for a link between microalbuminuria and endothelial dysfunction. The Hoorn Study. Kidney Int Suppl 2004;92: S42-S44.

38 de Jong PE, Brenner BM: From secondary to primary prevention of progressive renal disease: the case for screening for albuminuria. Kidney Int 2004;66:2109-2118.

39 Cho BS, Kim SD: School urinalysis screening in Korea. Nephrology 2007;12:S3-S7.

$\checkmark 40$ El Nahas AM: Global challenge of chronic kidney disease. Kidney Int 2005;68:29182929.
41 Pakasa NM, Sumaili EK: The nephrotic syndrome in the Democratic Republic of Congo. N Engl J Med 2006;354:1085-1086.

$42 \mathrm{~K} / \mathrm{DOQI}$ : Clinical practice guidelines for chronic kidney disease: evaluation, classification, and stratification. Kidney Disease Outcome Quality Initiative. Am J Kidney Dis 2002;39(2 suppl):S21-S266.

-43 Boulware LE, Jaar BG, Tarver-Carr ME, Brancati FL, Powe NR: Screening for proteinuria in US adults: a cost-effectiveness analysis. JAMA 2003;290:3101-3114.

\section{(c) Free Author Copy - for per- sonal use only PLEASE NOTETHAT ANY DISTRIBUTION OFTHIS AR- TICLE WITHOUT WRITTEN CONSENT FROM S. KARGER AG, BASEL IS A VIOLATION OFTHE COPYRIGHT \\ Upon request a written per- mission to distribute the PDF file will be granted against payment of a permission fee depending on the number of accesses required. Please contact Karger Publishers, Basel, Switzerland at permission@karger.ch}

